\title{
A new pseudodepsidone from the Antarctic lichen Stereocaulon alpinum and its antioxidant, antibacterial activity
}

\author{
Hari Datta Bhattarai ${ }^{1,3}$, Taikyung Kim ${ }^{1,3}$, Hyuncheol $\mathrm{Oh}^{2}$ and Joung Han Yim ${ }^{1}$ \\ The Journal of Antibiotics (2013) 66, 559-561; doi:10.1038/ja.2013.41; published online 15 May 2013
}

Keywords: antibacterial; depsidones; lichen metabolites; lobaric acid; Stereocaulon alpinum

Several species of lichens have been used for various remedies in folk medicine since ancient time and variety of biologically active lichen metabolites, including antibiotic, antimycobacterial, antiviral, analgesic, antioxidant and antipyretic properties, have been described. ${ }^{1}$ During surviving strategy against extreme environment, especially, high UV, Antarctic plants have been believed to produce unique types of metabolites. ${ }^{2}$ Several lichen species of the Antarctic origin have shown antibacterial and antioxidant activities. ${ }^{3-5}$ In our previous studies of isolation of bioactive metabolites from Antarctic lichens, lobaric acid and related metabolites showing protein tyrosine phosphatase 1B inhibitory activities have been isolated from Stereocaulon alpinum of Antarctic origin. ${ }^{6}$ Moreover, antibacterial and antioxidant activity showing compounds: ramalin and three new derivatives of usnic acids were isolated from Ramalina trebrata. ${ }^{7,8}$ In the course of our continuing study in this area, a structurally new pseudodepsidone-type metabolite, lobastin, was encountered from the new collection batch of $S$. alpinum from Antarctica. This report describes the isolation, structure elucidation and comparative biological activities including antimicrobial and antioxidant activities of the lobastin encountered in this study.

Antimicrobial activities were evaluated by determining zone of inhibition and MIC against Staphylococcus aureus, Escherichia coli, Bacillus subtilis, Candida albicans and Aspergillus niger. Antioxidant activity was estimated by determining DPPH (1-diphenyl-2-picrylhydazil) free radical-scavenging capacity. ${ }^{8,9}$ Brine shrimp lethality test ${ }^{10}$ was performed to evaluate the toxicity of the compounds (detail in Supplementary Information).

The compound $\mathbf{1}$ was isolated as white powder and identified as lobaric acid by analysis of MS and NMR data. ${ }^{11}$ Compound 2 (Figure 1, Supplementary Figures S1-8) was isolated as white powder. The compound was optically inactive. The molecular formula was established as $\mathrm{C}_{25} \mathrm{H}_{28} \mathrm{O}_{8}$ on the basis of HR-ESIMS data for $\mathrm{m} / \mathrm{z}$ $455.1701[\mathrm{M}-\mathrm{H}]^{-}$with 12 degrees of unsaturation. IR spectrum showed the presence of hydroxyl $\left(3232 \mathrm{~cm}^{-1}\right)$ and carbonyl $\left(1740 \mathrm{~cm}^{-1}\right)$ functionalities. The ${ }^{1} \mathrm{H}$ NMR spectrum clearly showed the presence of four aromatic/olefinic protons, a number of aliphatic protons and a methoxy group. The ${ }^{1} \mathrm{H}$ NMR data could not fully show the total proton number as shown in molecular formula, because some replaceable protons were not observed and some protons related to aliphatic chains were overlapped. The ${ }^{13} \mathrm{C} N M R$ data clearly showed the presence of 25 carbon signals including 14 olefinic carbons, suggesting the presence of a minimum of two aromatic rings. In addition, two carbonyl, one methoxy, two methyl and six methylene carbons were clearly observed. The structure of $\mathbf{2}$ was mainly elucidated based on the analysis of 2D NMR. The partial structures $\mathrm{C}-9$ to $\mathrm{C}-12$ and $\mathrm{C}-8^{\prime}$ to $\mathrm{C}-12^{\prime}$ were deduced from the careful analysis of the ${ }^{1} \mathrm{H}-{ }^{1} \mathrm{H}$ COSY and HSQC data of 2, along with comparisons of respective data with those for lobaric acid. The HMBC correlation of H-3 to C-1, C-2, C-3, C-5, C-7; H-5 to C-1, $\mathrm{C}-2, \mathrm{C}-3, \mathrm{C}-4, \mathrm{C}-8$ and $\mathrm{H}-3^{\prime}$ to $\mathrm{C}-1^{\prime}, \mathrm{C}-2^{\prime}, \mathrm{C}-4^{\prime}, \mathrm{C}-5^{\prime}, \mathrm{C}-7^{\prime}$ indicated the presence of two aromatic rings. The HMBC correlation of olefinic proton $\mathrm{H}-9$ to $\mathrm{C}-6$ and C-8 together with HMBC correlation of methylene proton $\mathrm{H}-10$ to C-8, C-9, C-11, C-12 (Table 1) confirmed the connection of a side chain with the olefinic carbon C-9. In fact, the structure of compound 2 was very close to that of previously encountered pseudodepsidone-type compound $3^{6}$ (Figure 1) and sakisacaulon A. ${ }^{12}$ Therefore, the presence of benzofurane moiety and biphenyl ether connection between C- 2 and C-5 $5^{\prime}$ were supported by comparision of the NMR data to those for compound 3 and sakisacaulon A. The absence of oxygenated methyl group at C-8 and the presence of a double bond in between C- 8 and C-9 in compound 2 were the structural differences with compound 3 . The observed NMR data clearly supported these structural differences in compound 2 with compound 3 and sakisacaulon A. Finally, NOESY correlation of $\mathrm{H}-5$ with $\mathrm{H}-9$ indicated that the double bond at C-8 and C-9 was in Z configuration, completing the gross structure of 2 as

${ }^{1}$ Division of Life Sciences, Korea Polar Research Institute, KOPRI, Incheon, Republic of Korea and ${ }^{2}$ College of Pharmacy, Wonkwang University, Iksan, Republic of Korea

3These authors contributed equally to this work.

Correspondence: Dr JH Yim, Division of Life Sciences, Korea Polar Research Institute, KOPRI, Incheon 406-840, Republic of Korea.

E-mail: jhyim@kopri.re.kr

Received 5 February 2013; revised 25 March 2013; accepted 2 April 2013; published online 15 May 2013 


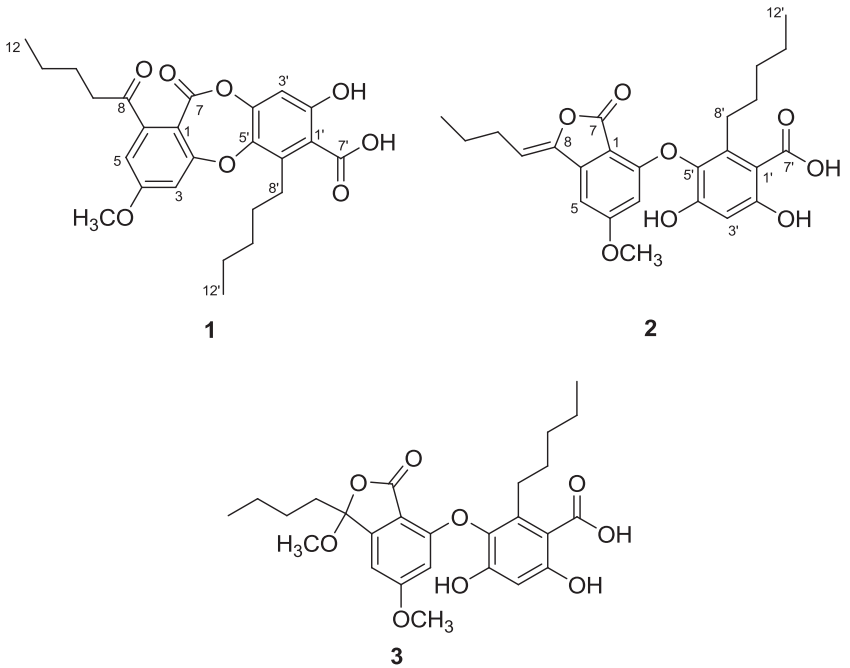

Figure 1 Structures of compounds $1-3$.

Table 1 NMR data for compound 2 (400 MHz, DMSO-d6)

\begin{tabular}{|c|c|c|c|}
\hline Position & $\delta_{C}$ & $\delta_{H}$, mult. $(J$ in $\mathrm{Hz})$ & $H M B C^{\ominus}$ \\
\hline 1 & 104.2 & - & - \\
\hline 2 & 157.4 & - & - \\
\hline 3 & 101.7 & $5.90, d(1.8)$ & $1,2,4,5,7$ \\
\hline 4 & 166.4 & - & - \\
\hline 5 & 96.7 & $7.19, \mathrm{~d}(1.8)$ & $1,2,3,4,8$ \\
\hline 6 & 143.4 & - & - \\
\hline 7 & 163.2 & - & - \\
\hline 8 & 144.9 & - & - \\
\hline 9 & 109.3 & $6.00, \mathrm{t}(7.7)$ & $6,8,10,11$ \\
\hline 10 & 27.3 & $2.36, \mathrm{~m}$ & $8,9,11,12$ \\
\hline 11 & 21.9 & $1.52, \mathrm{~m}$ & $9,10,12$ \\
\hline 12 & 13.6 & $0.96, t(7.0)$ & 10,11 \\
\hline $1^{\prime}$ & 108.4 & - & - \\
\hline $2^{\prime}$ & 158.2 & - & - \\
\hline $3^{\prime}$ & 101.9 & $6.41, \mathrm{~s}$ & $1^{\prime}, 2^{\prime}, 4^{\prime}, 5^{\prime}, 7^{\prime}$ \\
\hline $4^{\prime}$ & 153.2 & - & - \\
\hline $5^{\prime}$ & 131.8 & - & - \\
\hline $6^{\prime}$ & 137.3 & - & - \\
\hline $7^{\prime}$ & 171.2 & - & - \\
\hline \multirow[t]{2}{*}{$8^{\prime}$} & 27.5 & $2.70, \mathrm{~m}$ & - \\
\hline & & $2.52, \mathrm{~m}$ & \\
\hline \multirow[t]{2}{*}{$9^{\prime}$} & 29.5 & $1.39, \mathrm{~m}$ & - \\
\hline & & 1.27, m & \\
\hline $10^{\prime}$ & 31.4 & $1.12, \mathrm{~m}$ & - \\
\hline $11^{\prime}$ & 21.4 & $1.12, \mathrm{~m}$ & - \\
\hline $12^{\prime}$ & 13.56 & $0.69, \mathrm{t}(7.0)$ & $10^{\prime}, 11^{\prime}$ \\
\hline $4-\mathrm{OCH}_{3}$ & 56.3 & $3.79, \mathrm{~s}$ & 4 \\
\hline $4^{\prime}-\mathrm{OH}$ & - & $10.39, \mathrm{~s}$ & $3^{\prime}, 4^{\prime}, 5^{\prime}$ \\
\hline
\end{tabular}

Abbreviation: DMSO- $d 6$, Dimethyl sulfoxide- $d 6$.

a HMBC correlations, optimized for $8 \mathrm{~Hz}$, are from proton(s) stated to the indicated carbon(s).

shown. The structural similarity of compound 2 with lobaric acid 1 and compound 3 led to the speculation that compound 2 might be an artifact produced from either $\mathbf{1}$ or $\mathbf{3}$ during isolation process from the extract of S. alpinum. Therefore, direct HPLC-MS analysis of freshly prepared crude extract of $S$. alpinum was conducted in 6310 Agilent Ion Trap LC/MS, and the analysis (Supplementary Figure S9) indicated that the compound 2 (peak at $17.1 \mathrm{~min}$ ) was present in
Table 2 Antibacterial, antioxidant and toxicity activity of compounds 1 and 2

\begin{tabular}{|c|c|c|c|c|}
\hline Compound & Compound & & Berberine & \\
\hline 1 & 2 & Ampicillin $B H A$ & chloride & Remarks \\
\hline \multicolumn{5}{|c|}{ Inhibition zone (mm $100 \mu g^{-1}$ perdisk) } \\
\hline 14 & 20 & & & $\begin{array}{l}\text { Against } \\
\text { B. subtilis }\end{array}$ \\
\hline 13 & 16 & & & $\begin{array}{c}\text { Against } S . \\
\text { aureus }\end{array}$ \\
\hline \multicolumn{5}{|l|}{$M I C(\mu M)$} \\
\hline 88 & 44 & 2.7 & & $\begin{array}{l}\text { Against } \\
\text { B. subtilis }\end{array}$ \\
\hline 39.6 & 35.2 & 2.7 & & $\begin{array}{c}\text { Against } S \text {. } \\
\text { aureus }\end{array}$ \\
\hline
\end{tabular}

DPPH activity $(\mu \mathrm{M})$

$\begin{array}{lll}\text { No } & 70.2 & 26.6\end{array}$

activity

$(B S T)\left(L C_{50}\right)(\mu M)$

No No activity $\quad 22.6$

activity

Abbreviations: BHA, butylated hydroxyanisole; BST, Brine shrimp lethal test; Compound 1 lobaric acid; Compound 2, lobastin; ; DPPH, 1-diphenyl-2-picryl-hydazil.

the crude extract as $16.3 \%(\mathrm{w} / \mathrm{w})$. Similarly, compounds $\mathbf{1}$ (peak at $22.5 \mathrm{~min}$ ) and 3 (peak at $17.7 \mathrm{~min}$ ) were contained as 25.4 and $7.4 \%$, respectively. As the freshly prepared extract contained significant amount of compound 2, we concluded that compound 2 was not an artifact but a new natural product.

In the present experiment, lobaric acid 1 and lobastin 2 were active against Gram-positive bacteria, B. subtilis and S. aureus (Supplementary Figures S10-12). The paper disk diffusion assay $(100 \mu \mathrm{g} / \mathrm{disk})$ showed that the average zone of inhibition for compounds 1 and 2 were 14 and $20 \mathrm{~mm}$ against B. subtilis, and 13 and $16 \mathrm{~mm}$ in diameter against $S$. aureus, respectively. In addition, the MIC of compounds 1 and 2 were obtained as 88 and $44 \mu \mathrm{M}$ against B. subtilis, and 39.6 and $35.2 \mu \mathrm{m}$ against $S$. aureus, respectively. Both compounds 1 and 2 did not show antimicrobial activity against Gram-negative bacteria, C. albicans and A. niger.

Compound 2 reduced DPPH free radicals in dose-dependent manner. The obtained data (Table 2) indicated that compound 2 showed moderate antioxidant activity compared with the synthetic commercial standard butylated hydroxyanisole. Compound 1 did not show DPPH-reducing activity even at higher dose $(4000 \mu \mathrm{M})$. Perhaps, the presence of double bond in between C-8 and C-9, and opening of heterocyclic ring in compound 2 were responsible for such antioxidant activity of the molecule.

Both compounds $\mathbf{1}$ and $\mathbf{2}$ were tested with Brine shrimp larvae at various concentrations $(0-4000 \mu \mathrm{M})$. Both compounds did not show toxicity effects (Table 2). The commercial standard berberine chloride showed $\mathrm{LC}_{50}$ at $22.6 \mu \mathrm{m}$. In conclusion, this new compound 2, lobastin, showed moderate antioxidant and antibacterial activities. It did not show toxic effect to Artimia salina larvae. These data may suggest the possible use of this natural compound, lobastin, in future antioxidant therapy.

\section{ACKNOWLEDGEMENTS}

This work was supported by a grant to the Korea Polar Research Institute, KOPRI, under a project PE10200. 
1 Kumar, K. C. S. \& Müller, K. Lichen metabolites. J. Nat. Prod. 62, 817-820 (1999).

2 Rozema, J. et al. (Poly)phenolic compounds in pollen and spores of Antarctic plants as indicators of solar UV-B-A new proxy for the reconstruction of past solar UV-B? Plant. Ecol. 154, 9-26 (2001).

3 Bhattarai, H. D., Paudel, B., Hong, S. G., Lee, H. K. \& Yim, J. H. Thin layer chromatography analysis of antioxidant constituents of lichens from Antarctica. J. Nat. Med. 62, 481-484 (2008).

4 Paudel, B. et al. Antibacterial potential of Antarctic lichens against human pathogenic grampositive bacteria. Phytother. Res. 22, 1269-1271 (2008a).

5 Paudel, B. et al. Antioxidant activity of polar lichens from King Geroge Island (Antarctica). Polar Biol. 31, 605-608 (2008b).

6 Seo, C. et al. Protein tyrosine phosphatase 1B inhibitory effects of depsidone and pseudodepsidone metabolites from the Antarctic lichen Stereocaulon alpinum. Bioorg. Med. Chem. Lett. 19, 2801-2803 (2009).
7 Paudel, B. et al. Antibacterial activities of ramalin, usinc acid and its three derivatives isolated from the Antarctic lichen Ramalina terebrata. Z. Naturforsch 65c, 34-38 (2010).

8 Paudel, B. et al. Ramalin, a novel nontoxic antioxidant compound from the Antarctic lichen Ramalina terebrata. Phytomedicine 18, 1285-1290 (2011).

9 Blois, M. S. Antioxidant determinations by the use of a stable free radical. Nature 26, 1199-1200 (1958).

10 Meyer, B. N. et al. Brine shrimp: A convenient general bioassay for active plant constituents. Planta Med. 45, 31-34 (1982).

11 Elix, J. A., Wardlaw, J. H. \& Yoshimura, I. Sublobaric Acid and oxolobaric acid, two new depsidones from the Lichen Anzia hypoleucoides. Aust. J. Chem. 50, 763-765 (1997).

12 Morita, H. et al. Antimitotic activity of lobaric acid and a new benzofuran, sakisacaulon A from Stereocaulon sasakii. Bioorg. Med. Chem. Lett. 19, 3679-3681 (2009).

Supplementary Information accompanies the paper on The Journal of Antibiotics website (http://www.nature.com/ja) 